UCRL-TR-215214

LCLS-TN-05-26

September 12, 2005

\title{
LCLS Spontaneous Radiation with Reflection along the Beam Line in the Undulator Pipes ${ }^{*}$
}

\author{
K. W. Fong \\ Lawrence Livermore National Laboratory
}

\begin{abstract}
Monte Carlo simulations of the spontaneous radiation at low and high energies up to the Near Experimental Hall entrance yield beam widths for use in the design of transport and diagnostic instruments in the Front End Enclosure.

\section{Disclaimer}

This document was prepared as an account of work sponsored by an agency of the United States Government. Neither the United States Government nor the University of California nor any of their employees, makes any warranty, express or implied, or assumes any legal liability or responsibility for the accuracy, completeness, or usefulness of any information, apparatus, product, or process disclosed, or represents that its use would not infringe privately owned rights. Reference herein to any specific commercial product, process, or service by trade name, trademark, manufacturer, or otherwise, does not necessarily constitute or imply its endorsement, recommendation, or favoring by the United States Government or the University of California. The views and opinions of authors expressed herein do not necessarily state or reflect those of the United States Government or the University of California, and shall not be used for advertising or product endorsement purposes.
\end{abstract}

\footnotetext{
* This work was performed under the auspices of the U.S. Department of Energy by University of California, Lawrence Livermore National Laboratory under Contract W-7405-Eng-48.

Work supported in part by the DOE Contract DE-AC02-76SF00515. This work was performed in support of the LCLS project at SLAC.
} 


\section{LCLS Spontaneous Radiation with Reflection along the Beam Line in the Undulator Pipes}

Some commissioning and alignment procedures for XTOD may rely on the use of the spontaneous radiation. Therefore we have modeled the spontaneous radiation between the Undulator and the Near Experimental Hall to derive numerical values of the expected beam width and of the energy deposition. The values are then used to determine aperture sizes and detector sensitivities.

We performed the calculations in three stages. The first was to generate an appropriate distribution of photons within the Undulator. The second was to simulate the emergence of the photons from the Undulator. The third was to propagate the photons (without any obstructing objects) to various points along the Z-axis up to the Near Experimental Hall entrance. We performed the simulations for low and high energies based on the spectral flux data supplied by Sven Reiche. These data sets were at 71 meters from the end of the Undulator for 4.5 and $14.08 \mathrm{GeV}$ electrons.

In the first stage, we randomly generated ten million photons consistent with the spectral flux data. The initial photons were distributed uniformly in Z but only within the 33 Undulator segments each 3.4 meters long. The angular distribution was uniform about the $Z$-axis. The radial distribution was proportional to

$$
e^{\left(-\frac{1}{2} \frac{\text { radius }^{2}}{\sigma^{2}}\right)}
$$

where SIGMA was 30.1 microns. No photons were initially placed in the short and long breaks between Undulator segments.

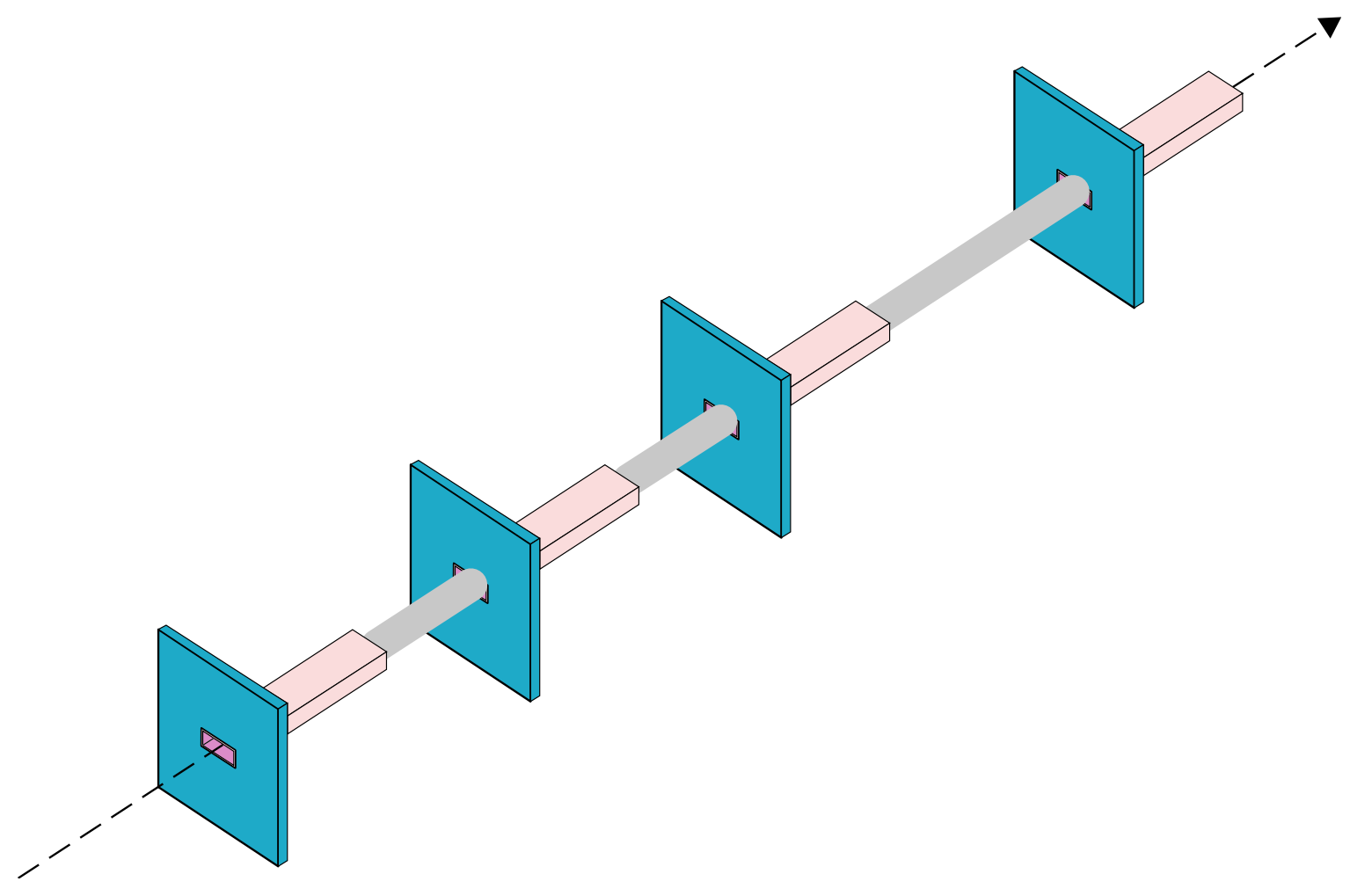


In the second stage, we propagated the photons through a model of the Undulator pipes out to $\mathrm{Z}=650$ meters. The diagram above (which is not drawn to scale) illustrates the model. The rectangular pipes were modeled as aluminum pipes with $1 \mathrm{~mm}$ thick walls, though in reality they are stainless steel with aluminum coating. Most of the rectangular pipes were 3.467 meters long except the pipes after long breaks that were 3.4665 meters long. The inside dimensions of the rectangular pipes were $5 \times 10 \mathrm{~mm}$. For modeling purposes, we wanted to stop any photons that escaped in the breaks from propagating down stream, so the model included baffles or collars at the front of each rectangular pipe consisting of tantalum one centimeter thick. In each break there are two circular pipes. Immediately after each rectangular pipe (except the last one) is an $8 \mathrm{~mm}$ inside diameter copper pipe coated with aluminum. This is the pipe through the quadrupole magnet. We modeled it as an aluminum tube. Following the $8 \mathrm{~mm}$ tube is a $10 \mathrm{~mm}$ inside diameter tube going down to the next rectangular pipe. This was also modeled as though it were an aluminum tube. The $8 \mathrm{~mm}$ tubes were $123.1 \mathrm{~mm}$ long. The $10 \mathrm{~mm}$ tubes were $143.2 \mathrm{~mm}$ in length for the short breaks and $708 \mathrm{~mm}$ for the long breaks. The remaining space was treated as low-pressure air. The propagation model included the photoelectric effect and high energy Compton scattering off of free electrons. The aluminum surfaces were modeled as perfectly reflecting, the consequence of which is that nearly all the energy emerges from the undulator. At low energy, $0.0059 \%$ is absorbed in the Undulator pipes while $99.9941 \%$ arrives at $Z=650$. At high energy, 0.0055\% is lost in the Undulator while $99.9945 \%$ arrives at $Z=650$. In our model, the Undulator started at $Z=515$ and ended at $Z=646.52$ with the last rectangular pipe extending $33.5 \mathrm{~mm}$ beyond the end of the Undulator.

The output of the second stage includes a database with all the photon locations, energies, and directions. The third stage of the calculation consists of repeated runs to propagate the photons from that database to 17 selected $\mathrm{Z}$ locations further downstream. At each destination $\mathrm{Z}$ we projected the photon energies to the $\mathrm{X}$-axis and fitted a Gaussian to the energy distribution. We likewise did a fit to the energy distribution projected on the Y-axis. The fundamental results are the sigmas of the $\mathrm{X}$ and $\mathrm{Y}$ Gaussian energy fits. Of course, the energy distributions are not true Gaussians, so the fits are only an approximation to the real distributions, but they are sufficient for choosing aperture sizes. In particular, the calculated Y distribution is a little narrower than the real distribution because the spectral flux data did not extend to large values of Y. Thus our initial photon distribution has few photons that will propagate to $\mathrm{Y}$ values that are larger than those in the spectra flux data. The table on the next page gives the sigmas in millimeters and the LCLS Z coordinate in meters. The LCLS Z coordinates are based on Pat Duffy's schematic of July 15, 2005 except the Fixed Mask and Slit A are one meter farther downstream than in the schematic. 


\begin{tabular}{|l|c|c|c|c|c|}
\hline Description & LCLS Z, $\mathrm{m}$ & $\begin{array}{c}\text { Low Energy } \\
\text { X Sigma, } \mathrm{mm}\end{array}$ & $\begin{array}{c}\text { Low Energy } \\
\text { Y Sigma, mm }\end{array}$ & $\begin{array}{c}\text { High Energy } \\
\text { X Sigma, mm }\end{array}$ & $\begin{array}{c}\text { High Energy } \\
\text { Y Sigma, mm }\end{array}$ \\
\hline & 655.000 & 14.61 & 3.824 & 4.697 & 1.305 \\
\hline & 665.000 & 17.81 & 4.734 & 5.702 & 1.561 \\
\hline & 675.000 & 20.84 & 5.563 & 6.653 & 1.816 \\
\hline & 685.000 & 23.74 & 6.345 & 7,566 & 2.062 \\
\hline & 695.000 & 26.57 & 7.097 & 8.453 & 2.299 \\
\hline Fixed Mask & 705.000 & 29.35 & 7.827 & 9.321 & 2.532 \\
\hline Slit A & 708.475 & 30.30 & 8.077 & 9.619 & 2.612 \\
\hline FEE Entrance & 710.207 & 30.78 & 8.200 & 9.767 & 2.651 \\
\hline Gas Atten. Ent. & 722.000 & 33.98 & 9.033 & 10.77 & 2.917 \\
\hline Gas Atten. Exit & 727.528 & 35.48 & 9.418 & 11.23 & 3.040 \\
\hline Solid Attenuator & 733.528 & 37.10 & 9.834 & 11.73 & 3.173 \\
\hline WFOVDI & 740.700 & 37.76 & 10.00 & 11.99 & 3.242 \\
\hline Mirror Tank A Ent. & 743.190 & 39.03 & 10.33 & 12.32 & 3.333 \\
\hline Mirror Tank B Ent. & 746.875 & 40.69 & 10.50 & 12.53 & 3.388 \\
\hline Mirror Tank C Ent. & 751.190 & 41.85 & 11.04 & 13.19 & 3.562 \\
\hline NEH Entrance & 757.404 & 43.52 & 11.46 & 13.70 & 3.698 \\
\hline
\end{tabular}

The following is an example of a histogram of the energy projected onto the $\mathrm{X}$-axis at the wide field of view direct imager located at LCLS $\mathrm{Z}=740.7 \mathrm{~m}$. The teal colored curve shows the Gaussian fit. The charge propagated was $4.79 \times 10^{-6} \mathrm{nC}$.

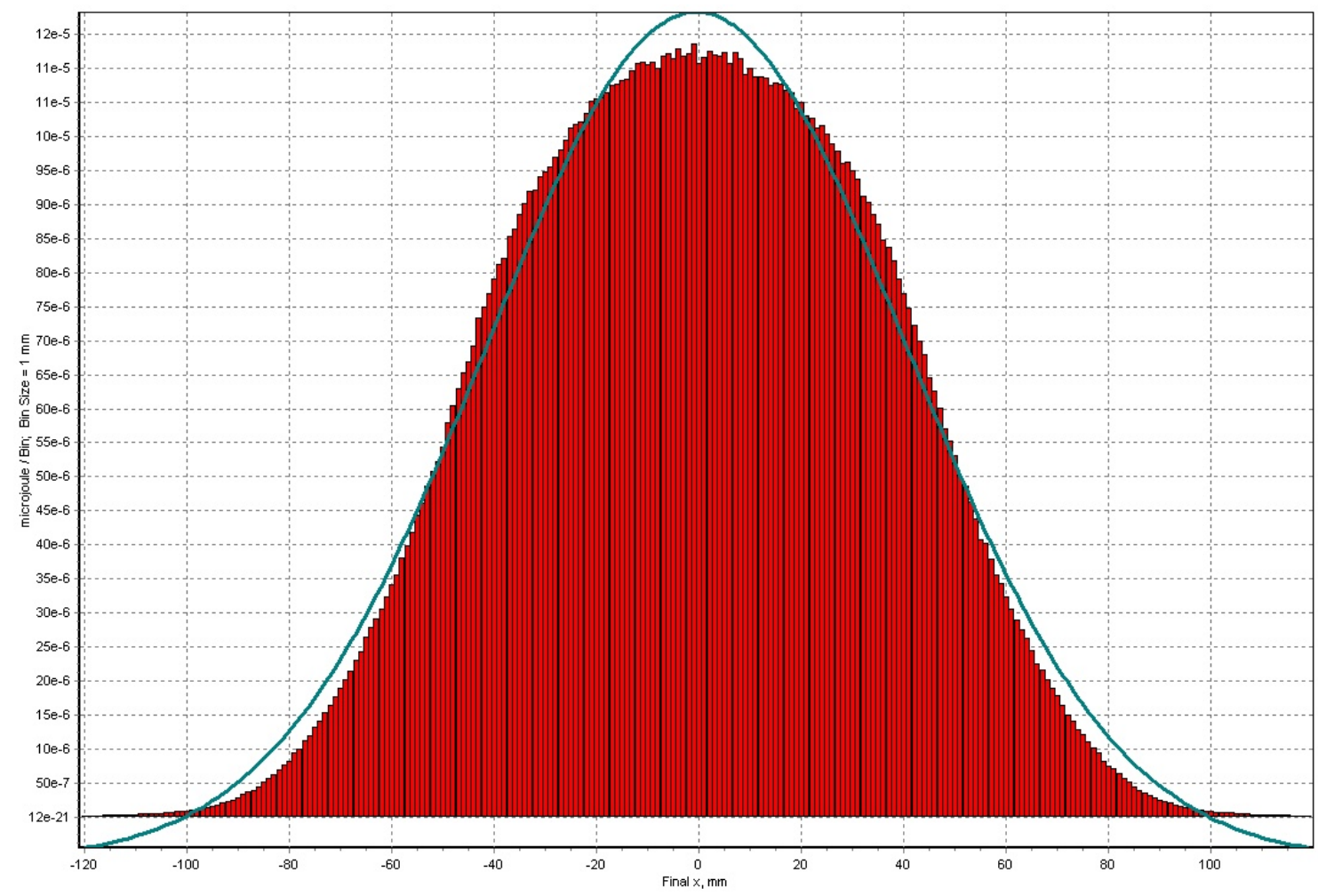


The scatter plot below is of the energy at the wide field of view direct imager.

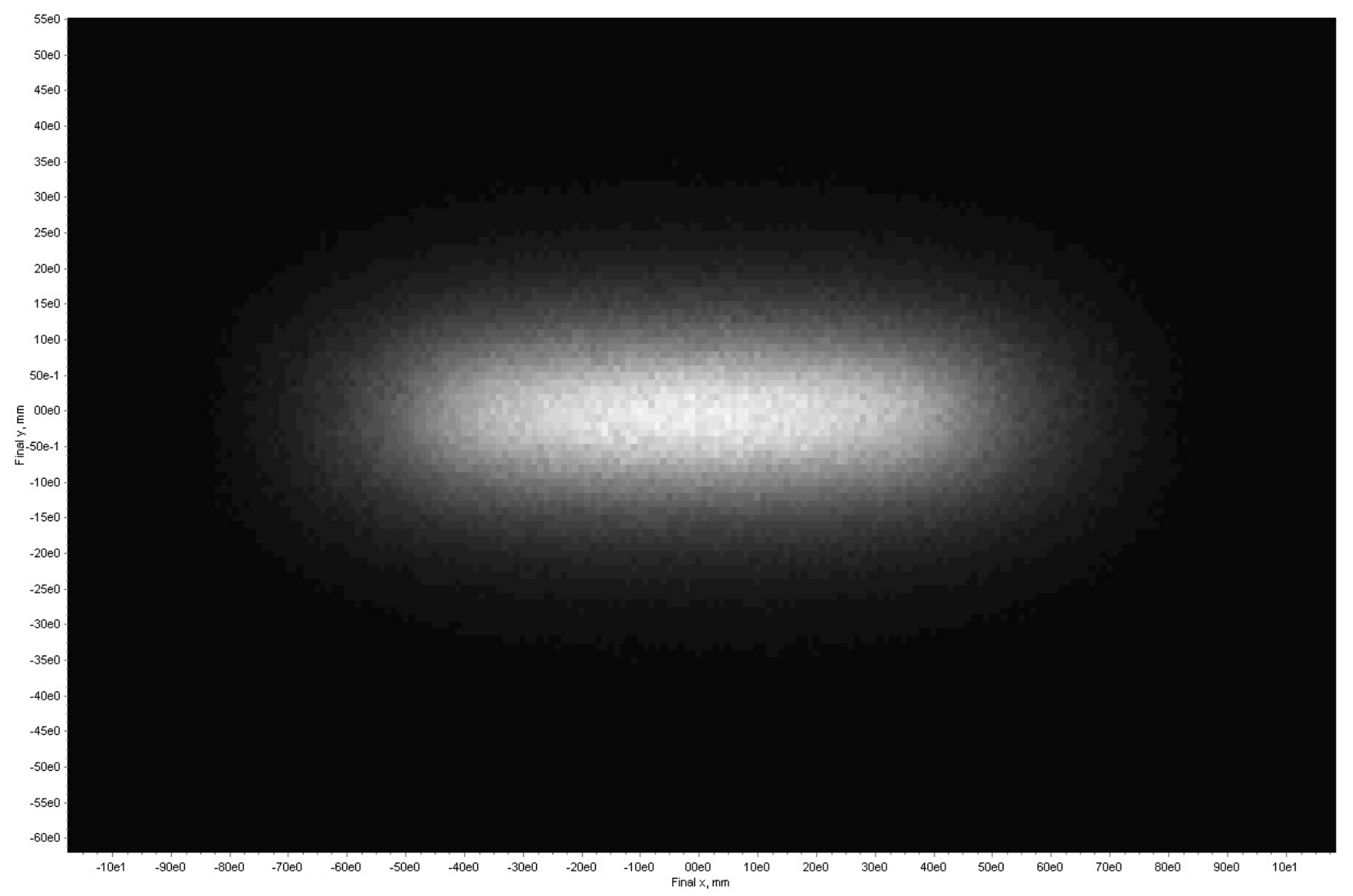

We summarize the results with plots of the numbers in the above table. One plot is for low energy and another is for high energy. Each plot contains six lines. The dashed green lines are the $\mathrm{X}$ and $\mathrm{Y}$ sigma as a function of $\mathrm{Z}$ but doubled in order to give the diameter or beam width. For a true Gaussian distribution, an aperture width the size of the $\mathrm{X}$ green line and the height of the $\mathrm{Y}$ green line would permit $68 \%$ of the energy to pass. The dotted blue lines are triple the dashed green lines and therefore encompass what would be $99.73 \%$ of the energy if the Gaussian fit actually were the energy distribution. In a similar fashion, the solid red lines are 1.1774 times the green lines and are the full width half max or $76 \%$ of the energy. 


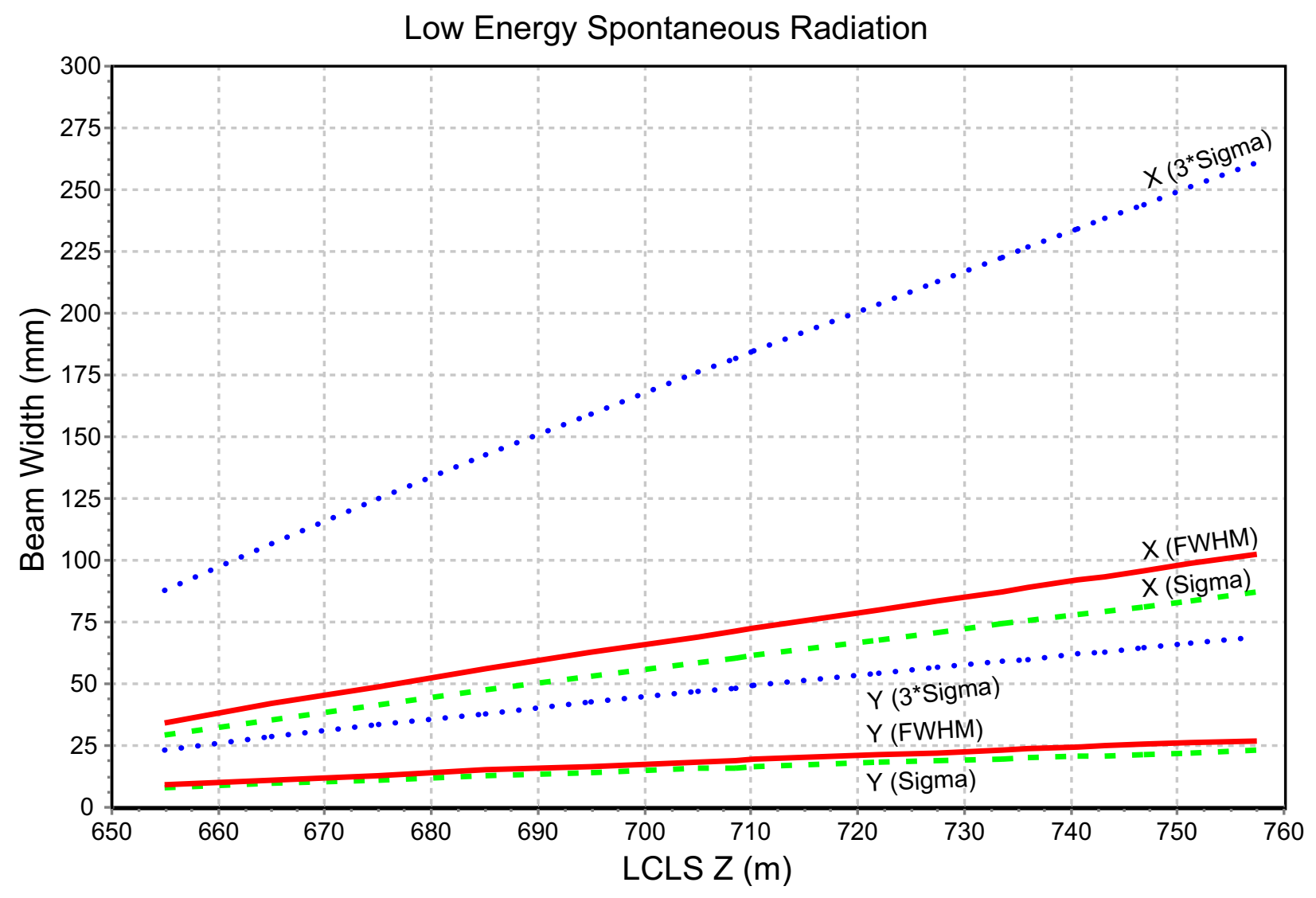


High Energy Spontaneous Radiation

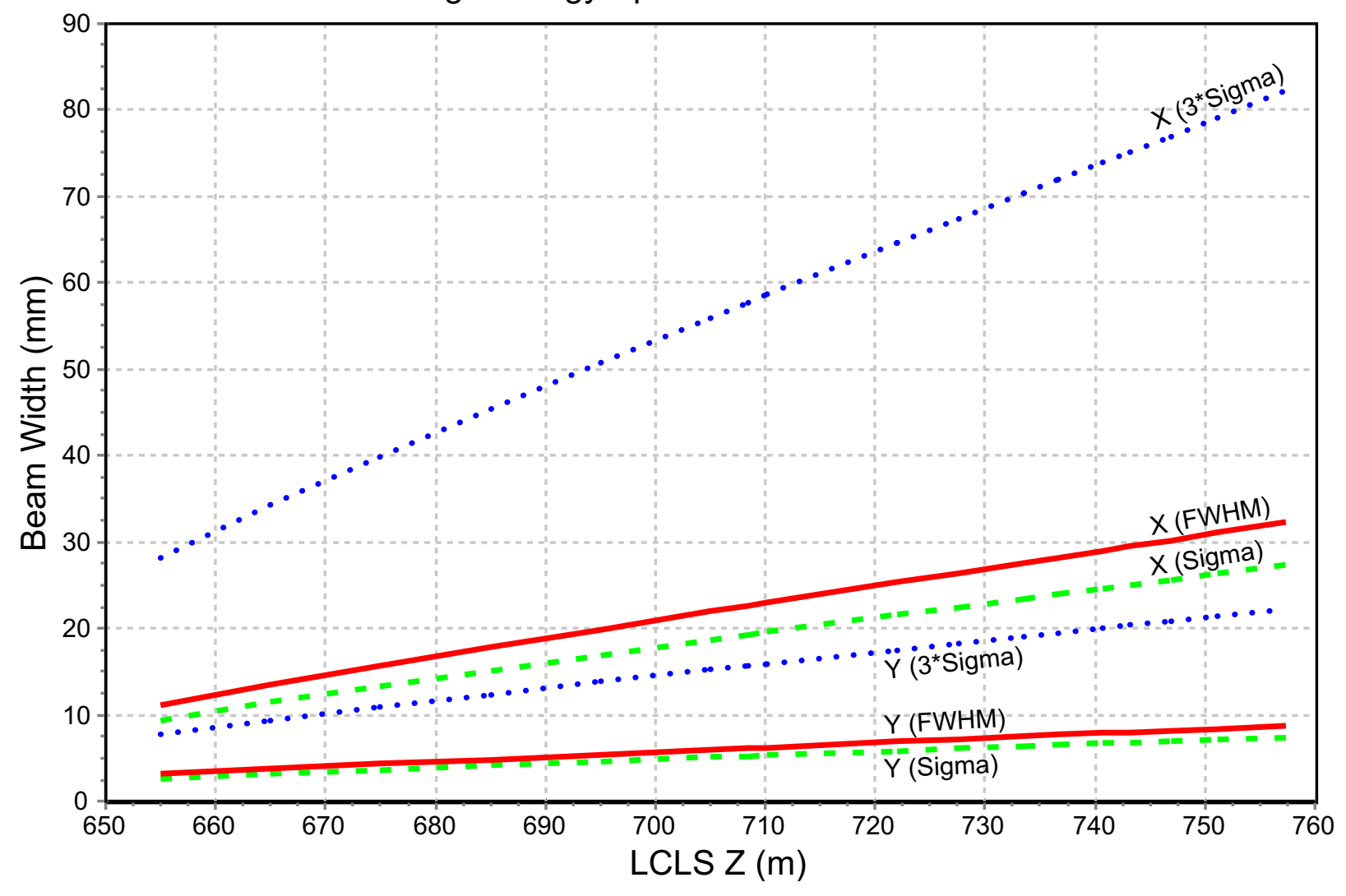

